\title{
No Higher Risk of CRPS After External Fixation of Distal Radial Fractures - Subgroup Analysis Under Randomised Vitamin C Prophylaxis ${ }^{\S}$
}

\author{
Paul E. Zollinger ${ }^{*}, 1$, Robert W. Kreis ${ }^{2}$, Hub G. van der Meulen ${ }^{3}$, Maarten van der Elst ${ }^{4}$, \\ Roelf S. Breederveld ${ }^{5}$ and Wim E. Tuinebreijer ${ }^{5}$
}

\author{
${ }^{I}$ Department of Orthopaedic Surgery, Ziekenhuis Rivierenland, Pres. Kennedylaan 1, 4002 WP Tiel, The Netherlands \\ ${ }^{2}$ Department of Burn Wounds and Department of Surgery, Red Cross Hospital, Beverwijk and Free University Hospital, \\ Amsterdam, The Netherlands \\ ${ }^{3}$ Department of Surgery, Haga Hospital, The Hague, The Netherlands \\ ${ }^{4}$ Department of Surgery, Reinier de Graaf Group, Delft, The Netherlands \\ ${ }^{5}$ Department of Surgery, Red Cross Hospital, Beverwijk, The Netherlands
}

\begin{abstract}
Operative and conservative treatment of wrist fractures might lead to complex regional pain syndrome (CRPS) type I.

In our multicenter dose response study in which patients with distal radial fractures were randomly allocated to placebo or vitamin $\mathrm{C}$ in a daily dose of $200 \mathrm{mg}, 500 \mathrm{mg}$ or $1500 \mathrm{mg}$ during 50 days, an operated subgroup was analyzed.

48 (of 427) fractures) were operated (11.2\%). Twenty-nine patients (60\%) were treated with external fixation, 14 patients $(29 \%)$ with K-wiring according to Kapandji and five patients $(10 \%)$ with internal plate fixation. The 379 remaining patients were treated with a plaster.

In the operated group of patients who received vitamin C no CRPS (0/37) was seen in comparison with one case of CRPS (Kapandji technique) in the operated group who received placebo $(1 / 11=9 \%, p=.23)$. There was no CRPS after external fixation.

In the conservatively treated group 17 cases of CRPS $(17 / 379=4.5 \%)$ occurred in comparison with one in case of CRPS in the operated group $(1 / 48=2.1 \%, \mathrm{p}=.71)$.

External fixation doesn't necessarily lead to a higher incidence of CRPS in distal radial fractures. Vitamin C may also play a role in this. This subgroup analysis in operated distal radial fractures showed no CRPS occurrence with vitamin C prophylaxis.
\end{abstract}

Keywords: Ascorbic acid, complex regional pain syndrome, external fixators, radius fractures, reflex sympathetic dystrophy, vitamin $\mathrm{C}$.

\section{INTRODUCTION}

The management of distal radial fractures is usually conservative. Patients are treated with a plaster of Paris cast or splint, after reduction if necessary.

If conservative treatment of a wrist fracture is not possible, closed reduction with external fixation, closed reduction with internal fixation or open reduction with internal fixation can be the choice of treatment.

*Address correspondence to this author at the Department of Orthopaedics, Ziekenhuis Rivierenland Tiel, P.O. Box 6024, 4000 HA Tiel, The Netherlands; Tel: +31344674217 ; Fax: +31344632903 ;

E-mail: PE.ZZollinger@tiscali.nl

${ }^{\S}$ The participants in this study are three hospitals in the Netherlands: The surgical department of the Red Cross Hospital in Beverwijk, The orthopaedic and surgical department of the Haga Hospital (location Leyenburg) in the Hague and The orthopaedic and surgical department of the Reinier de Graaf Group in Delft.
In some cases a Complex Regional Pain Syndrome (CRPS) type I will develop. In literature there is a great variation in incidence of CRPS after wrist fractures from $1 \%$ up to $37 \%[1,2]$. In an earlier report we described an incidence of $22 \%$ in a control group [3].

In the past it has been suggested that external fixation might lead to a high incidence of CRPS, up to 33\% [4]. Later data show an incidence of CRPS of $19 \%$ after external fixation [5]. Part of the problem in diagnosing CRPS is that there are different criteria used worldwide to describe CRPS type I, formerly known as reflex sympathetic dystrophy (RSD) [6-8]. There is no golden standard yet for the diagnosis of CRPS.

On the other hand, different treatment modalities are used for different indications in wrist fractures. For extra-articular distal radial fractures the treatment is usually different than for fracture types with intra-articular comminution or open fractures. 
We performed a secondary analysis of our randomised controlled multicenter dose response study, which investigated the effect of three different doses of vitamin C on the incidence of CRPS type 1 [9]. The subgroup consisted of distal radial fractures that were treated operatively. We selected a group of patients treated with external fixation and a group with internal fixation. Patients treated conservatively with a plaster of Paris formed the control group.

\section{MATERIAL AND METHODOLOGY}

\section{Study Design}

The study was set up as a multicenter prospective cohort. Three hospitals in the Netherlands participated in this study. Adults (18 years or above) with a wrist fracture who were seen in the emergency department were asked to participate in the study.

All types of wrist fractures were included. Fracture types were classified according to the AO/ASIF classification [10]. It was left to the decision of the surgeon how the patient was treated. Operative treatment varied from closed reduction and external fixation, over closed reduction and internal fixation (Kapandji) to open reduction and internal fixation (ORIF) [11]. The external fixation method in our study was a bridging technique.

Conservative treatment consisted of a plaster of Paris cast for four or five weeks, if necessary after closed reduction under local anesthesia.

In our primary study patients were randomly allocated to vitamin $\mathrm{C}$ or a placebo. In this procedure informed consent had to be obtained from each patient. The medical ethics committees from the three hospitals had approved the study.

From day one patients received a daily dosage of 200, 500 or $1500 \mathrm{mg}$ of vitamin $\mathrm{C}$ or a placebo for 50 consecutive days. This procedure was a double blinded one and only the hospitals pharmacist knew the allocation code.

As we are more familiar in the Netherlands with the criteria of Veldman, we used these to establish the diagnosis of CRPS I [8].

Complex regional pain syndrome type I was diagnosed when four of the following five symptoms were present at the wrist, including the area distal to the wrist (hand and fingers), and if they occurred (or increased) after activity:

1. unexplained diffuse pain, not in normal relation to the stage of fracture treatment;

2. difference in skin colour relative to the other hand an wrist;

3. diffuse oedema;

4. difference in skin temperature relative to the other hand and wrist;

5. 5.limited active range of motion of the wrist and fingers, unrelated to the stage of fracture treatment [8].

The diagnosis of CRPS was made by a physician in the treating department and not by anyone involved in the conduct of the trial. All the patients with CRPS had pain.

The follow-up period was one year.

\section{Statistical Analysis}

The statistical analysis was performed with SPSS (version 11.0) software on a personal computer. Sample and group sizes were estimated a priori using results of our previous study, a planned power of $90 \%$ and a significance $(\alpha)$ of 0.05 [3].

The chi-square test, Likelihood ratio test, Fisher's exact test, ANOVA and Student's $t$ test were used as applicable for univariate analysis. A post hoc power calculation was done on the proportions of CRPS comparing the operated group and the non-operated group with $\mathrm{G}^{*}$ Power software (version $3.03)$.

\section{RESULTS}

In this secondary study we compared distal radial fractures that had to be operated on with conservatively treated fractures with a follow-up of one year. We prospectively included 48 patients with fractures who had to undergo surgery in some sort of form. These 48 fractures represented $11.2 \%$ of all distal radial fractures treated during the study.

Of these patients $29(60 \%)$ were treated with an external fixator. In this group of external fixation there were, according to the AO/ASIF classification, 7 A type and $22 \mathrm{C}$ type fractures [10].

The operated patients and those treated conservatively $(\mathrm{N}=379)$ did not differ significantly in terms of demography (Table 1). Analysis of the operated and conservative treated groups showed no significant differences for the variables of sex, age, fracture side, dominance and cast-related complaints (Table 1).

A total of 14 patients $(29 \%)$ were treated with K-wires according to Kapandji [11].

In this subgroup were, again according to the AO/ASIF classification, $8 \mathrm{~A}$ type, $2 \mathrm{~B}$ type and $4 \mathrm{C}$ type fractures (Table 2).

Five patients $(10 \%)$ in our cohort underwent an open reduction and internal fixation with a plate. This small group consisted of 1 A type, 2 B type and $2 \mathrm{C}$ type fractures (Table 2).

In these 48 operated wrist fractures only in one case (2.1\%) a CRPS type I was diagnosed (Table 1). In the external fixator group there was no CRPS. The only case of CRPS was seen in the Kapandji group (7\%), in a patient receiving placebo treatment.

In the operated group (Table 3 ) who received vitamin $C$ no CRPS (0/37) was seen in comparison with one patient with CRPS in the operated group who received placebo $(1 / 11=9 \%, p=.23)$.

The conservatively treated control group counted 379 fractures (Table 2). In this conservatively treated group 17 cases of CRPS $(17 / 379=4.5 \%)$ occurred in comparison with one CRPS in the operated group $(1 / 48=2.1 \%, \mathrm{p}=.71)$.

The type of operation in relation to the fracture type is shown in Table 2. As one might expect, the external fixator is more often used in the more comminuted fractures ( $\mathrm{AO}$ type C). As expected in the operated groups significant more 


\section{Table 1. Demography of Intervention}

\begin{tabular}{|c|c|c|c|}
\hline \multicolumn{4}{|l|}{ Gender (no. of fractures) } \\
\hline Female & $37(77.1 \%)$ & $315(83.1 \%)$ & \\
\hline Male & $11(22.9 \%)$ & $64(16.9 \%)$ & 0.301 \\
\hline Right & $21(43.8 \%)$ & $173(45.6 \%)$ & \\
\hline Left & $27(56.3 \%)$ & $206(54.4 \%)$ & 0.804 \\
\hline \multicolumn{4}{|l|}{ Dominance (no. of fractures) } \\
\hline Yes & $25(52.1 \%)$ & $174(46 \%)$ & \\
\hline $23-\mathrm{A}$ & $16(33.3 \%)$ & $215(56.7 \%)$ & \\
\hline 23-B & $4(8.3 \%)$ & $86(22.7 \%)$ & \\
\hline $23-\mathrm{C}$ & $28(58.3 \%)$ & $78(20.6 \%)$ & 0.000 \\
\hline \multicolumn{4}{|l|}{ Dislocation (no. of fractures) } \\
\hline Yes & $47(97.9 \%)$ & $237(62.5 \%)$ & \\
\hline No & $1(2.1 \%)$ & $142(37.5 \%)$ & 0.000 \\
\hline \multicolumn{4}{|l|}{ Reduction (no. of fractures) } \\
\hline Yes & $45(93.8 \%)$ & $217(57.3 \%)$ & \\
\hline Vitamin C 500mg & $15(31.3 \%)$ & $99(26.1 \%)$ & \\
\hline Vitamin C $1500 \mathrm{mg}$ & $12(25 \%)$ & $106(28 \%)$ & \\
\hline Vitamin C overall & $37(77.1 \%)$ & $291(76.8 \%)$ & 0.891 \\
\hline \multicolumn{4}{|l|}{ CRPS (no. of fractures) } \\
\hline Yes & $1(2.1 \%)$ & $17(4.5 \%)$ & \\
\hline No & $47(97.9 \%)$ & $362(95.5 \%)$ & 0.707 \\
\hline
\end{tabular}

${ }^{*}$ The values are given as the mean of the standard deviation.

dislocations were seen and therefore significant more reductions were performed (Table 1). The equal distribution of placebo and vitamin $\mathrm{C}$ over the different subgroups is shown in Table 1.

The distribution of the operations over the different departments is shown in Table 4.

This shows that the Kapandji method is exclusively conducted in one hospital. This method is equally distributed over the surgery and orthopedic department.

The external fixation treatment is divided regularly over the three hospitals.
Table 2. Operative Treatment of Fracture Type (AO/ASIF Classification)

\begin{tabular}{|l|c|c|c|}
\hline & A Fractures & B Fractures & C Fractures \\
\hline \hline External fixation & $7(43.8 \%)$ & $0(0 \%)$ & $22(78.6 \%)$ \\
\hline Internal fixation (ORIF) & $1(6.3 \%)$ & $2(50 \%)$ & $2(7.1 \%)$ \\
\hline Kapandji method & $8(50 \%)$ & $2(50 \%)$ & $4(14.3 \%)$ \\
\hline total & 16 & 4 & 28 \\
\hline
\end{tabular}


Table 3. CRPS in the Operative Subgroep Comparing Vitamin C with Placebo

\begin{tabular}{|l|c|c|c|}
\hline & $\begin{array}{c}\text { CRPS } \\
\text { No. of Fractures } \\
(\mathbf{\%})\end{array}$ & $\begin{array}{c}\text { CRPS } \\
\text { No. of Fractures } \\
(\mathbf{\%})\end{array}$ & p Value \\
\hline \hline & Yes & No & \\
\hline Vitamin C overall & $0(.0 \%)$ & $37(78.7 \%)$ & \\
\hline Placebo & $1(100 \%)$ & $10(21.3 \%)$ & 0.229 \\
\hline
\end{tabular}

Table 4. Hospital and Operative Treatment

\begin{tabular}{|l|c|c|c|c|}
\hline \multicolumn{1}{|c|}{ Hospital } & $\begin{array}{c}\text { External } \\
\text { Fixation }\end{array}$ & $\begin{array}{c}\text { Internal } \\
\text { Fixation } \\
\text { (ORIF) }\end{array}$ & $\begin{array}{c}\text { Kapandji } \\
\text { Method }\end{array}$ & $\begin{array}{c}\text { Conservative } \\
\text { Treatment }\end{array}$ \\
\hline \hline Reinier de Graaf & $11(37.9 \%)$ & $1(20 \%)$ & $0(0 \%)$ & $126(33.2 \%)$ \\
\hline Haga Hospital & $10(34.5 \%)$ & $2(40 \%)$ & $14(100 \%)$ & $117(30.9 \%)$ \\
\hline $\begin{array}{l}\text { Red Cross } \\
\text { Hospital }\end{array}$ & $8(27.6 \%)$ & $2(40 \%)$ & $0(0 \%)$ & $136(35.9 \%)$ \\
\hline total & 29 & 5 & 14 & 379 \\
\hline
\end{tabular}

$\mathrm{P}=0.001 ;$ no. of fractures (\%).

The post-hoc calculated power for finding a difference between the proportion of CRPS in the operated vitamin C group $(0 / 37=0 \%)$ and the proportion of CRPS in the operated non-vitamin $\mathrm{C}$ group $(1 / 11=9.1 \%)$ was $26 \%$ (alpha .05 ).

\section{DISCUSSION}

It has often been suggested that CRPS has a higher incidence after an external fixator, than after other methods of operative treatment $[4,12,13]$. The reason for this seems unclear. Is it because of distraction or is the comminuted intra-articular fracture the cause $[3,12]$ ?

Different studies show different results in therapy for distal radius fractures and different results in outcome and complication rate, especially for CRPS.

Kaempffe et al. diagnosed retrospectively five cases of RSD in a group of 26 patients (19\%) treated with external fixation for their distal radius fracture [14].

McQueen et al. diagnosed 3 patients with RSD (10\%) and one with a shoulder-hand-syndrome in a group of 31 fractures treated with external fixation [15].

Sennwald et al. report 5 patients with RSD from a group of 30 patients treated with an external fixator (17\%) [16].

Harley has 3 cases of RSD out of 25 patients (12\%) [17].

Finally Suso et al. report even 17 cases of RSD out of a group of 30 patients (60\%) [13]. These studies are in number of patients comparable with our own study.

Two frequently cited randomised clinical trials concerning external fixation in Colles' fractures are from Howard and Roumen $[18,19]$. Howard et al. studied a group of 50 patients with severely displaced comminuted fractures and randomised them for treatment with an external fixator or manipulation plaster [18]. In their study they found a similar percentage of fractures treated with operation (12\%) as we did in our present study. This percentage of operated fractures is comparable low and is probably the result of a non-aggressive style of treatment, i.e. non-operative style. CRPS type I is not a complication in their study, but they don't give a definition of this clinical entity. Complications that Howard et al. saw were radial neuritis (8\%), median nerve compression (8\%) and ulnar nerve compression (4\%). Nowadays these findings would be described as CRPS type II. In their study radial neuritis was seen in $4 \%$ after an external fixator and in $12 \%$ after conservative treatment.

Roumen et al. studied the results from external fixation after redisplacement of a conservatively treated wrist fracture in patients over 55 years of age [19]. Their main complication was RSD: 14 cases out of 101 patients (14\%). Unfortunately the criteria for the diagnosis were not mentioned, nor in the reference they referred to.

Twenty-one patients were randomized to treatment with an external fixator after redisplacement and 22 for further conservative treatment. Four patients $(19 \%)$ with an external fixator developed RSD and 2 patients (9\%) with conservative treatment. In the 58 patients with conservative treatment and no displacement of the fracture there was RSD in 8 cases (14\%). Carpal tunnel syndrome was seen in another 12 patients (12\%) and none of them had RSD.

Hegeman et al. compared a primary external fixation with a plaster immobilization in intra-articular unstable distal radial fractures in 32 elderly [5]. In this study 5 patients developed CRPS $(16 \%)$ as defined according to the Veldman criteria. There was one case of CRPS in the 17 patients treated with a cast $(6 \%)$ and there were 4 patients with CRPS in the group of 15 patients treated with an external fixator (27\%).

In another article Hegeman reports CRPS in 3 patients from a group of 16 intra-articular unstable distal radial fractures treated with an external fixator (19\%) [20].

In comparison we saw a low incidence (2.1\%) of CRPS in our operated group and no CRPS after an external fixator. An explanation for this might probably be a prophylactic effect of vitamin C. Vitamin $\mathrm{C}$ was shown to be effective in preventing CRPS in conservative treated radial fractures by our study group in two randomized clinical trials [3, 9].

Cazeneuve et al. demonstrated the same effect of vitamin C in a cohort study of patients who had to undergo surgical treatment for their distal radius fractures by intrafocal pinning [21].

In general in literature an increase for surgical treatment of distal radial fractures is recognized. As there are no universally accepted criteria for an adequate reduction in displaced wrist fractures, the indication for conservative treatment is floating away towards the direction of surgical treatment. Volar plate fixation with locking plates is becoming popular. While plate fixation may allow earlier motion than six weeks of cast immobilization, no differences in motion, pain, strength or function were seen after three or six months postoperatively according to a review by Amadio in 2008 [22].

Complication rates of distal radial fractures differ for the applied treatments and they are lowest in the casting group (11\%). After surgery more complications occur than are generally appreciated (31 and $37 \%$ for plate and external fixation) [22]. 
The complications of volar plate fixation are extensively discussed in a recent review by Berglund. CRPS has been reported after volar plate fixation in 3 to $10 \%$ [23].

In our present study the sample size of the operated group was too small to yield a significant difference in CRPS prevention between the vitamin $\mathrm{C}$ and placebo treated operated groups. The operated placebo group consisted of eleven patients leading to a low power of this subgroup analysis $(26 \%)$ and probably to a type II error (false negative). The incidence of CRPS in our operated patients is non-significant lower than in patients treated with a plaster cast. This last comparison between the operated and conservative group had also insufficient power to find a possible significant difference. In a Cochrane review Handoll et al. reported from different studies $6.5 \%$ CRPS in the external fixator group and $4.9 \%$ CRPS in the conservative plaster cast group [24].

An adequately powered study is necessary to provide evidence, not only for the incidence of CRPS but also to determine the relative effects of different methods of external fixation [25].

\section{CONCLUSION}

We conclude that external fixation doesn't necessarily lead to a higher incidence of CRPS in distal radial fractures. To our opinion vitamin $\mathrm{C}$ lowers the incidence of CRPS in nonoperatively treated wrist fractures and may also play a role in operatively treated wrist fractures. This subgroup analysis in operated distal radial fractures showed no CRPS occurrence with vitamin $\mathrm{C}$ prophylaxis and gives us further arguments for a new prospective study to gather a large number of patients for sufficient statistical analysis.

\section{ACKNOWLEDGEMENTS}

We thank Napoleon Coene and Rolf Bloem, orthopedic surgeons at the Haga Hospital and the Reinier de Graaf Group for their clinical management.

This work was kindly supported by a grant from "Stichting Achmea Slachtoffer en Samenleving (SASS)", a Dutch foundation for encouraging research objectives in relation to 'aid to victims'.

\section{REFERENCES}

[1] Atkins RM, Duckworth T, Kanis JA. Features of algodystrophy after Colles' fracture. J Bone Joint Surg Br 1990; 72: 105-10.

[2] Dijkstra PU, Groothoff JW, Duis ten HJ, Geertzen JHB. Incidence of complex regional pain syndrome type I after fractures of the distal radius. Eur J Pain 2003; 7: 457-62.

[3] Zollinger PE, Tuinebreijer WE, Kreis RW, Breederveld RS. Effect of vitamin $\mathrm{C}$ on frequency of reflex sympathetic dystrophy in wrist fractures: A randomised trial. Lancet 1999; 354: 2025-8.

[4] Raay van JJAM, Boot C, Oostvogel HJM, Werken van der C. External fixation of unstable distal radius fractures (Article in Dutch with English summary). Ned Tijdschr Geneeskd 1990; 134; 1607-11.

[5] Hegeman JH, Oskam J, Palen van der J, Ten Duis ten HJ, Vierhout PAM. Primary external fixation of the intra-articular unstable distal radial fracture in the elderly. Akt Traumatol 2004; 34: 64-70.
[6] Bruehl S, Harden RN, Galer BS, et al. External validation of IASP diagnostic criteria for Complex Regional Pain Syndrome and proposed research diagnostic criteria. International Association for the Study of Pain. Pain 1999; 81: 147-54.

[7] Merskey H, Bogduk N, Eds. Classification of chronic pain: Descriptions of chronic pain syndromes and definitions of pain terms. $2^{\text {nd }}$ ed. Seattle: IASP Press 1994.

[8] Veldman PHJM, Reynen HM, Arntz IE, Goris RJA. Signs and symptoms of reflex sympathetic dystrophy: Prospective study of 829 patients. Lancet 1993; 342: 1012-6.

[9] Zollinger PE, Tuinebreijer WE, Breederveld RS, Kreis RW. Can vitamin C prevent Complex Regional Pain Syndrome in patients with wrist fractures? A randomized, controlled, multicenter dose-response study. J Bone Joint Surg Am 2007; 89: 1424-31.

[10] Müller ME, Nazarian S, Koch P, Schatzker J. The comprehensive classification of fractures of long bones. Berlin: Springer-Verlag 1990.

[11] Kapandji A. Bone fixation by double percutaneous pinning. Functional treatment of non-articular fractures of the lower end of the radius. Ann Chir Main 1976; 6: 903-8.

[12] Gradl G, Steinborn M, Wizgall I, Mittlmeier T, Schürmann M. [Acute CRPS I (Morbus Sudeck) following distal radial fracturesmethods for early diagnosis] (Article in German). Zentralbl Chir 2003; 128: 1020-6.

[13] Suso S, Combalia A, Segur JM, Garcia-Ramiro S, Ramon R Comminuted intra-articular fractures of the distal end of the radius treated with the Hoffmann external fixator. J Trauma 1993; 35: 61-6.

[14] Kaempffe FA, Wheeler DR, Peimer CA, Hvisdak KS, Ceravolo J, Senall J. Severe fractures of the distal radius: Effect of amount and duration of external fixator distraction on outcome. J Hand Surg Am 1993; 18: 33-41.

[15] McQueen MM, Michie M, Court-Brown CM. Hand and wrist function after external fixation of unstable distal radial fractures. Clin Orthop Relat Res 1992; 285: 200-4.

[16] Sennwald GR, Della Santa D. Unstable distal radial fractures treated by external fixation: Ananlytical review. Scan J Plast Reconstr Surg Hand Surg 2002; 36: 226-30.

[17] Harley BJ, Scharfenberger A, Beaupre LA, Jomha N, Weber DW. Augmented external fixation versus percutaneous pinning and casting for unstable fractures of the distal radius-a prospective randomized trial. J Hand Surg Am 2004; 29: 815-24.

[18] Howard PW, Stewart HD, Hind RE, Burke FD. External fixation or plaster for severely displaced comminuted Colles' fractures? A prospective study of anatomical and functional results. J Bone Joint Surg $\operatorname{Br} 1989 ; 71$ : 68-73.

[19] Roumen RMH, Hesp WLEM, Bruggink EDM. Unstable Colles' fractures in elderly patients. A randomised trial of external fixation for redisplacement. J Bone Joint Surg Br 1991; 73: 307-11.

[20] Hegeman JH, Oskam J, Vierhout PA, Duis ten HJ. External fixation for unstable intra-articular distal radial fractures in women older than 55 years. Acceptable functional end results in the majority of the patients despite significant secondary displacement. Injury $2005 ; 36$ : 339-44.

[21] Cazeneuve JF, Leborgne JM, Kermad K, Hassan Y. Vitamine C et prévention du syndrome douloureux régional complexe de type 1 après fracture du radius distal traitée chirurgicalement. Acta Orthop Belg 2002; 68: 481-4.

[22] Amadio PC. What's new in hand surgery. J Bone Joint Surg Am 2008; 90: 453-8.

[23] Berglund LM, Messer TM. Complications of volar plate fixation for managing distal radius fractures. J Am Acad Orthop Surg 2009; 17: 369-77.

[24] Handoll HH, Huntley JS, Madhok R. External fixation versus conservative treatment for distal radial fractures in adults. Cochrane Database Syst Rev 2007; 3: CD006194.

[25] Handoll HH, Huntley JS, Madhok R. Different methods of external fixation for treating distal radial fractures in adults. Cochrane Database Syst Rev 2008; 1: CD006522. 